\title{
Effect of Metoclopramide and Bethanechol on Gastric Emptying in Infants
}

\author{
PAUL E. HYMAN, CANDY ABRAMS, AND ANDRE DUBOIS \\ Harbor-UCLA Medical Center, Torrance, California 90509 and Uniformed Services \\ University, Bethesda, Maryland 20014
}

\begin{abstract}
In a double-blind, placebo controlled study of 10 infants with upper gastrointestinal motor disorders, metoclopramide (1 mg/kg, intravenous) but not bethanechol (0.075 $\mathrm{mg} / \mathrm{kg}$, subcutaneous), signficantly increased the fractional rate of gastric emptying following a 5\% glucose meal. Infants were tested on 3 consecutive days with a phenol red dye-dilution technique which, if combined with acid titration of gastric samples, permits simultaneous measurements of gastric volume, fractional emptying rate, fluid output, and acid output. Metoclopramide increased the fractional emptying rate in eight of 10 infants (mean \pm SE increasing from $4.6 \pm 0.6$ to $7.3 \pm 1.0 \% / \mathrm{min}, p<0.02$ ). Neither drug altered gastric acid secretion, but metoclopramide significantly increased gastric fluid output (mean $\pm \mathrm{SE}$ increased from $3.5 \pm 0.6$ to $6.5 \pm 1.4 \mathrm{ml} / \mathrm{min}, p<$ $0.02)$. No undesirable side effects or complications occurred during testing. We conclude that trials are warranted to assess the clinical efficacy of metoclopramide in infants with nonobstructive causes of delayed gastric emptying. (Pediatr Res 19: 1029-1032, 1985)
\end{abstract}

\section{Abbreviatio
FER fractional emptying rate}

Infants with signs and symptoms of disordered upper gastrointestinal motility are often treated with bethanechol (Urecholine, Merck, Sharp, Dohme, Inc., Westpoint, PA) or metoclopramide (Reglan, A. H. Robbins, Inc., Richmond, VA) although neither drug has been approved by the FDA for this usage. In trials with infants, both drugs appeared to increase basal lower esophageal sphincter pressure, and reduce gastroesophageal reflux (1-5).

Delayed gastric emptying is commonly associated with gastroesophageal reflux in infants (6). Moreover, gastric stasis may be the more prominent abnormality in several conditions common to infants such as functional ileus in the low birth weight infant (7), or postoperative ileus in infants who have undergone surgery under general anesthesia.

The purpose of the present study was to evaluate the efficacy of metoclopramide and bethanechol in increasing gastric emptying in infants with signs and symptoms of disordered upper gastrointestinal motility.

\section{METHODS}

The study protocol was approved by the Human Subjects Committee of Harbor-UCLA Medical Center on September 3,

Received February 26, 1985; accepted May 24, 1985.

Address correspondence to Paul E. Hyman, M.D., Harbor-UCLA Medical Center, 1000 West Carson Street, C-1 Trailer, Torrance, CA 90509.

Supported in part by NIH-GCRC Grant RR00425 and A. H. Robbins, Inc
1983. Informed written consent was obtained from the parents of each infant prior to study.

Clinical data for each patient are summarized in Table 1. Ten infants referred consecutively for evaluation of recurrent vomiting or upper gastrointestinal motility disorders were each studied on 3 consecutive days.

On a separate day esophageal manometry was performed with the standard slow pull-through technique using a triple-lumen water perfused catheter in the seven infants whose symptoms included vomiting. Mean lower esophageal sphincter pressures are provided in Table 1.

Of the infants listed in Table 1, patients 1-7 were fed enterally, patient 8 received $50 \%$ of his calories enterally, and patients 9 and 10 received total parenteral nutrition. None of the infants appeared to be undernourished grossly. None appeared edematous or marasmic at the time of study. Weight for length plots of the patients $>3.0 \mathrm{~kg}$ ranged from 10 th -75 th percentile (8).

The gastric fractional emptying rate (the percentage of the meal leaving the stomach per minute, in $\% / \mathrm{min}$ ), gastric fluid output $(\mathrm{ml} / \mathrm{kg} / \mathrm{h})$ and gastric acid output $(\mu \mathrm{mol} / \mathrm{kg} / \mathrm{h})$ were determined using a dye dilution technique previously described and validated $(9,10)$. Infants were fasted for at least $4 \mathrm{~h}$ prior to the study. Intravenous infusion of dextrose and electrolyte solutions were permitted to continue in three infants. Small infants were studied while being cradled comfortably in the arms of a research nurse. Older infants sat in the nurse's lap during test sessions. A 10 French sump tube was placed through the nasoor oropharynx into the stomach, and the stomach was emptied of residual contents. Proper positioning of the tube in the most dependent portion of the stomach was verified by immediate recovery of $100 \%$ of an injection of water. Following a $30-\mathrm{min}$ stabilization period, a $2.5-\mathrm{ml}$ sample of mixed gastric contents was aspirated and, immediately thereafter, $5.0 \mathrm{ml}$ of water with phenol red $(50 \mathrm{mg} / \mathrm{dl})$ was introduced into the stomach. After mixing the added volume with gastric contents for $1 \mathrm{~min}$, a second $2.5-\mathrm{ml}$ sample of gastric fluids was aspirated. These procedures were repeated every $10 \mathrm{~min}$ during a 40 -min fasting period, and at $5,10,20,30,40,50$, and $60 \mathrm{~min}$ following intragastric administration of the test meal. The meal of $15 \mathrm{ml} /$ $\mathrm{kg} 5 \%$ dextrose was adjusted to $\mathrm{pH} 7.0$ and $37^{\circ} \mathrm{C}$, and contained phenol red $(5 \mathrm{mg} / \mathrm{dl})$. Five to seven min prior to the meal, each infant received an injection of either $1 \mathrm{mg} / \mathrm{kg}$ of metoclopramide by slow intravenous push, $0.075 \mathrm{mg} / \mathrm{kg}$ bethanechol subcutaneous, or $0.3 \mathrm{ml}$ saline placebo subcutaneous, given in random order on 3 separate days. During a careful review by the investigators and the Human Subjects Committee, these doses were agreed upon as representing the maximally effective doses and routes which could be administered with an acceptable margin of safety to infants. The injections were given in the absence of the investigators by a research nurse who did not participate in any other aspect of this study. During each study, dressings were applied to both a thigh and antecubital fossa to insure blinding of the investigators.

The concentration of phenol red in each sample was measured 
Table 1. Summary of clinical characteristics and FER for the infants

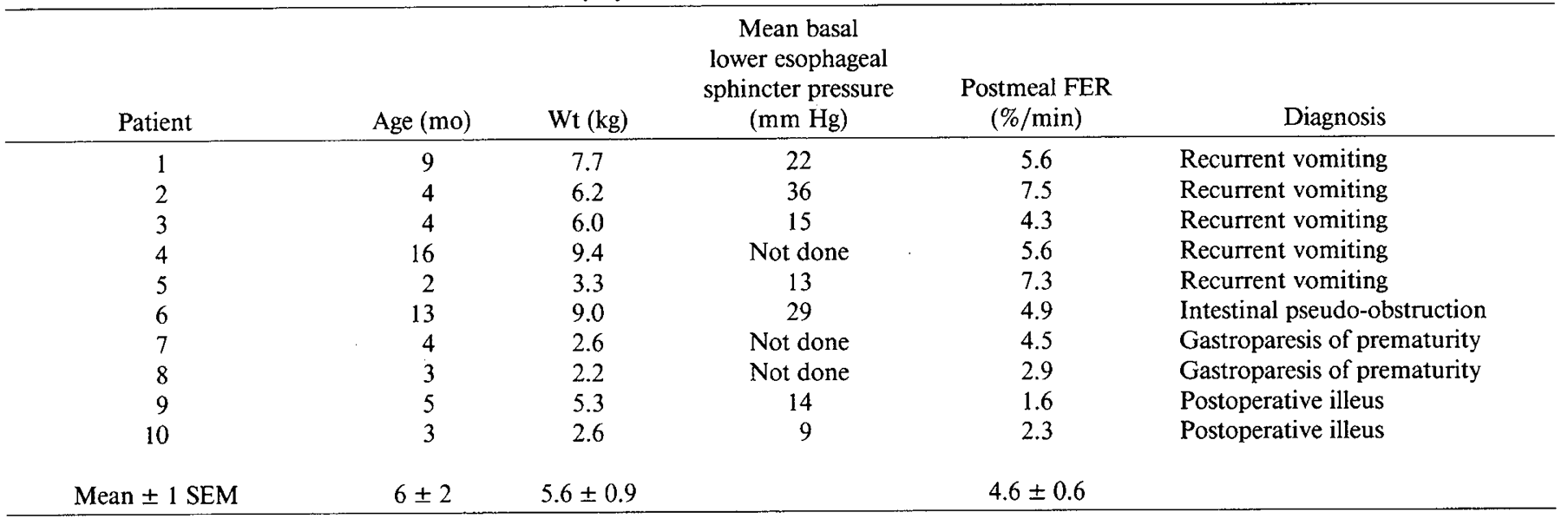

using a visible light spectrophotometer at $560 \mathrm{~nm}$ (Guilford Instruments Laboratories, Inc., Oberlin, $\mathrm{OH}$ ). The concentration of acid in each sample was measured by endpoint titration to $\mathrm{pH}$ 7.0 with a Radiometer TTT 60 titrator and ABU 60 autoburette (Radiometer, Inc., Copenhagen, Denmark). Intraassay variability was less than $5 \%$ while interassay variability was less than $20 \%$.

Intragastric volumes of fluid $\left(\mathrm{V}_{1}, \mathrm{~V}_{2} \ldots\right)$ and masses of phenol red $\left(P_{1}, P_{2}, \ldots\right)$ were determined at the time of each sampling using the dye dilution principle (9-12). Fractional emptying rate (g) was then determined for each 5- or 10-min interval between two dilutions $(\mathrm{t})$, assuming that emptying was a first order process (expotential) during short time intervals and using appropriate transformation of equation:

$$
P_{2}=P_{1} \exp (-g \cdot t)
$$

Net rate of fluid output $\left(R_{W}\right)$ was then determined for the corresponding interval, assuming that it remained constant over the given interval and using appropriate transformation of equation:

$$
\mathrm{V}_{2}=\mathrm{V}_{1} \exp (-\mathrm{g} \cdot \mathrm{t})+\mathrm{R}_{\mathrm{w}}(1-\exp (-\mathrm{g} \cdot \mathrm{t}) / \mathrm{g}
$$

Intragastric volume of fluid and masses of phenol red were then recalculated, taking into account these first estimates of fractional emptying and secretory rates, which were in turn recalculated. This interative process was repeated until the change of the calculated fractional emptying became less than $1 \%$ of its value per iteration $(9,10)$. Similar calculations were used to determine the amounts of intragastric $\mathrm{H}^{+}$at the time of each sampling and the net $\mathrm{H}^{+}$secretory rates. In addition to the determination of fractional emptying rate, this method thus permits simultaneous measurement of net fluid output (expressed as the volume secreted, in $\mathrm{ml}$ ) and of net $\mathrm{H}^{+}$secretion (in $\mu \mathrm{eq} / \mathrm{min}$ ). Slightly modified equations were used for the interval corresponding to the liquid test load to account for its intragastric administration $(9,10)$.

These calculations were performed using a locally developed program and a PDP-10 computer (Division of Computer Research and Technology, National Institutes of Health, Bethesda, MD). The assumptions involved and the validation of the method have been described and discussed elsewhere $(9,10)$. The present technique allows correlation for emptying and fluid output occurring during the 1-min dye dilution interval and can be applied both during fasting and following a liquid load.

Values obtained during the second to fourth 10 -min premeal intervals were averaged for each individual to provide basal data while allowing the establishment of a fasting steady state (9). Values from the first ( $0-5 \mathrm{~min})$ and second $(5-10 \mathrm{~min})$ postmeal time points were averaged. This value was averaged together with the third through seventh postmeal time points to provide one mean postmeal fractional emptying rate per subject and per day.
Table 2. Effect of metoclopramide and bethanechol on gastric functions (values are mean $\pm S E M$ )

\begin{tabular}{lccc}
\hline & $\begin{array}{c}\text { FER } \\
(\% / \mathrm{min})\end{array}$ & $\begin{array}{c}\text { Acid output } \\
(\mu \mathrm{mol} / \mathrm{kg} / \mathrm{h})\end{array}$ & $\begin{array}{c}\text { Fluid output } \\
(\mathrm{ml} / \mathrm{kg} / \mathrm{h})\end{array}$ \\
\hline Basal & $5.5 \pm 0.9$ & $46 \pm 4$ & $1.9 \pm 0.1$ \\
After meal & & & \\
$\quad$ Placebo & $4.6 \pm 0.6$ & $111 \pm 17$ & $3.5 \pm 0.6$ \\
$\quad$ Metoclopramide & $7.3 \pm 1.0^{*}$ & $124 \pm 15$ & $6.5 \pm 1.4^{*}$ \\
Bethanechol & $5.1 \pm 1.0$ & $143 \pm 16$ & $4.9 \pm 0.9$ \\
\hline
\end{tabular}

$* p<0.02$, compared to placebo.

In this manner each 10 -min interval carried the same weight. The significance of differences between pre- and postmeal values and between placebo and drug values was determined using an analysis of variance with repeated measures and subsequent $t$ tests $(9,10)$.

\section{RESULTS}

After placebo, the mean postcibal gastric FER was not significantly different from the fasting FER. In contrast, mean postcibal FER gastric fractional emptying rate was significantly faster following treatment with intravenous metoclopramide compared to placebo (Table 2). Metoclopramide increased FER by $20 \%$ or more in eight of 10 infants (Fig. 1). In contrast, bethanechol did not significantly alter FER. In the eight patients who responded to metoclopramide, the greatest effect on FER occurred during the initial 10 min following the meal. Averaging the FER for the 5 and 10 min time points, FER after placebo was $4.9 \pm 1.7 \%$ / min, after metoclopramide $21.1 \pm 10.0 \% / \mathrm{min}$, and after bethanechol $16.5 \pm 8.5 \% / \mathrm{min}$. At $10 \mathrm{~min} 38 \%$ of the meal had emptied after placebo, in contrast to $64 \%$ after metoclopramide (Fig. 2).

Gastric acid secretion increased 2- to 3-fold following the meal, a rise which was statistically significant $(p<0.01)$. Meal-stimulated acid secretion was not significantly altered by metoclopramide or bethanechol (Table 2). The maximal increase in acid secretory rate was evident from 20 to $30 \mathrm{~min}$ after instillation of the meal, with a return to fasting levels of acid secretion from 30 to $60 \mathrm{~min}$ after the meal.

Fluid output increased nearly 2-fold above fasting levels following the meal, a rise whch was statistically significant $(p<$ 0.01 ). Metoclopramide, but not bethanechol, caused a further significant $86 \%$ increase above values with placebo (Table 2). Metoclopramide increased fluid output in nine of 10 infants. In contrast, the trend of increased fluid output following bethanechol was not statistically significant.

There were no visible side effects attributable to metoclopramide or bethanechol as assessed by the person performing the 


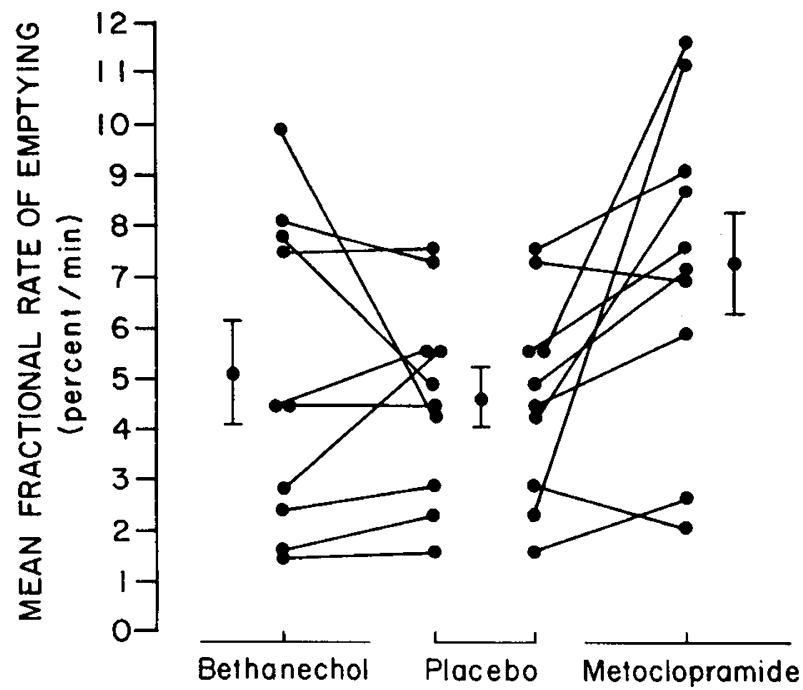

Fig. 1. Fractional emptying rates for individual infants, comparing bethanechol, placebo, and metoclopramide. Each dot represents an individual value; each bar represents the mean $\pm 1 \mathrm{SE}$.

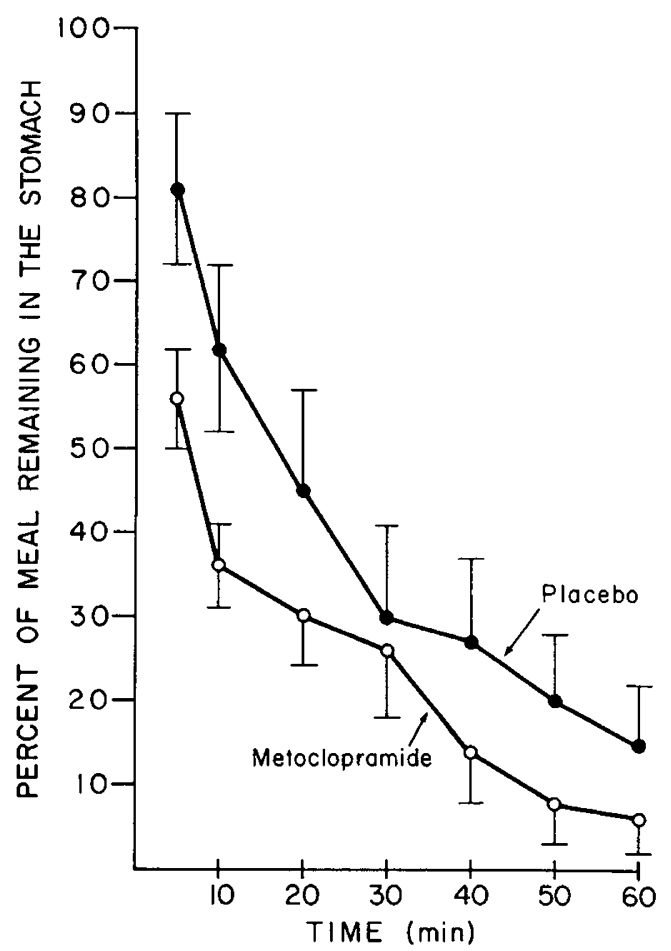

Fig. 2. Percentage of meal remaining in the stomach over time following placebo and metoclopramide in eight infants. Values are mean \pm SE.

study. Transient increases in blood pressure and pulse occurred immediately following all injections, but did not persist beyond the period of the patient's agitation in response to the injection.

\section{DISCUSSION}

Metoclopramide increased mean postcibal FER of a $5 \%$ glucose meal in eight of 10 infants referred for evaluation of an upper gastrointestinal motility disorder. Bethanechol significantly increased FER in only two of these infants. Both drugs were given in a dose thought to be safe and maximally effective, based on historical data $(3,13)$. Both drugs were given by injection to avoid individual variability in gastrointestinal absorption and thus to insure maximal pharmacologic effects 10 to 30 min following drug administration $(3,14)$. The results of this study in infants are similar to those obtained in adults: McCallum et al. (15) reported that metoclopramide, but not bethanechol, increased the rate of gastric emptying of a mixed solid-liquid meal in adults with delayed gastric emptying.

Although there were no studies of FER in normal infants available for comparison with the present study population, fasting FER in studies of healthy adults were $9.5 \% / \mathrm{min}(16), 10$ $\pm 1 \% / \mathrm{min}(17)$ and $12.2 \pm 2.5 \% / \mathrm{min}(18)$ or about twice the fasting FER observed in the infants we studied. In the infants, the fastest postmeal emptying rates were $5.6-7.5 \% / \mathrm{min}$ in a group referred for symptoms related to recurrent vomiting. In previous studies of adults, mean FER increased slightly to $13.6 \%$ after water alone, but was significantly reduced to $3.8 \pm 0.9 \%$ after a $30 \%$ glucose meal (18). However, gastric emptying did not appear to be delayed following liquid meals containing up to $15 \%$ of glucose (19). Thus, mean postcibal FER in our series was about one-half that observed in healthy adults. It appeared that the infants with FER $\geq 5.6 \% / \mathrm{min}$ may have either normal or mildly delayed gastric emptying. In contrast, infants with overt clinical evidence of gastric retention had fractional emptying rates of $1.6-4.5 \% / \mathrm{min}$, values which therefore appeared to reflect moderate to severe delay in gastric emptying.

Thus, the heterogeneity in the patient population was apparent not only in the signs and symptoms which prompted referral, but also in the results of the gastric emptying studies. The study design, in which each individual subject's study with placebo served as a control for drug effects, allowed valid evaluations. Despite the heterogeneity in results following placebo, eight of 10 infants responded to metoclopramide with significantly increased gastric emptying rates.

The gastric dye dilution technique used in the present study had several advantages over radionuclide imaging as a method for determining gastric empyting rate in a research setting. In contrast to radionuclide imaging, it did not require exposure to radiation, however low the level would be. Furthermore, validation experiments demonstrated that a good agreement existed between FER determined with the dye dilution technique and with radionuclide imaging of ${ }^{99 \mathrm{~m}} \mathrm{Tc}$-DTPA (9). In our studies, feeding the infants through a nasogastric tube assured standardized timing and volume of feedings for all studies of all patients. Such precision could not be maintained during oral feedings. The dye dilution technique with repeated sampling directly measured intragastric volume. Further calculations permitted measurements of the FER and volume secretion. Moreover, similar equations were used to calculate the rate of acid secretion. Thus, the dye dilution technique offered the possibility of measuring changes in a number of physiologic processes, whereas radionuclide imaging measures only emptying of the radionuclide. The emptying of solid meals could not be measured with the present technique, but because the infant diet is mainly liquids, this disadvantage appeared irrelevant.

The rate of gastric emptying of liquids depends on receptive relaxation (the ability of the stomach to accommodate to distension), followed by slow, sustained tonic contractions of the proximal stomach (20). Metoclopramide, a dopamine antagonist, inhibited receptive relaxation in dogs, presumably because gastric relaxation is mediated by the stimulation of dopamine receptors (21). In contrast, bethanechol and other cholinergic agonists do not interfere with gastric receptive relaxation. A possible explanation for the difference in efficacy between the two medications was that metoclopramide, but not bethanechol, inhibited receptive relaxation.

The mean basal acid output was $20 \%$ higher than we reported for healthy infants in an earlier study (22). The meal resulted in a transient increase in acid secretion with a time course identical to that reported previously for infants (23), but nearly double in quantity. These discrepancies may have resulted from differences among the study populations; however, it is more likely that the lower values in the early studies reflect incomplete recovery of 
gastric secretions, because the present dye-dilution method corrected for pyloric losses.

Fluid output increased following the meal in all subjects. One earlier study of infant formula-stimulated secretion determined that eight healthy infants secreted $2.0 \mathrm{ml} / \mathrm{kg}$ during the first 30 min postcibal interval (24). The present study is the first which permits comparison of basal secretory rates to meal-stimulated rates in infants. An unexpected finding was the significant increase in fluid output following metoclopramide. Although increased gastric fluid output has not been reported following injection of metoclopramide in laboratory animals or adult men, our observations suggest that this medication may increase gastric fluid output in infants. There is little clinical effect from the increase in volume secretion with metoclopramide, because the extra volume is small relative to the size of the meal.

Metoclopramide, given in a single intravenous bolus of $1 \mathrm{mg} /$ $\mathrm{kg}$, rapidly increased the FER in the majority of infants, and was not associated with side effects. In contrast, dystonic side effects were common in oncology patients receiving repeated intravenous infusions of metoclopramide (25). Extrapyramidal disturbances are reported to occur during treatment with oral metoclopramide, especially after overdose (26-30). Anecdotally, we treated five of our patients with oral metoclopramide $(0.15$ and $0.75 \mathrm{mg} / \mathrm{kg} /$ day), for periods that ranged from 1 to 2 months. No side effects were reported in these patients. Further studies are required to confirm the clinical usefulness of metoclopramide for the treatment of infants with delayed gastric emptying. It will be important to determine the lowest dose of drug which improves gastric emptying, and thus provide the highest margin of safety.

Acknowledgment. The authors thank Ms. Diane Warpack for expert secretarial assistance.

\section{REFERENCES}

1. Moroz SP, Espinoza J, Cumming WA, Diamant NE 1976 Lower esophageal sphincter function in children with and without gastroesophageal reflux. Gastroenterology 71:236-241

2. Euler AR 1980 Use of bethanechol for the treatment of gastroesophageal reflux. J Pediatr 96:321-324

3. Whitington PF, Shermeta DW, Seto DSY, Jones L, Hendrix TR 1977 Role of lower esophageal sphincter incompetence in recurrent pneumonia after repair of esophageal atresia. J Pediatr 91:550-554

4. Byrne WJ, Marino LR 1984 Metoclopramide increases lower esophageal sphincter pressure and reduces the number of episodes and duration of reflux in infants with gastroesophageal reflux. Pediatr Res 18:191A

5. Leung ARC, Lai PCW 1984 Use of metoclopramide for the treatment of gastroesophageal reflux in infants and children. Curr Ther Res 36:911-915

6. Hillemeier AC, Lange R, McCallum R, Seashore J, Gryboski J 1981 Delayed gastric emptying in infants with gastroesophageal reflux. J Pediatr 98:190193

7. Sankaran K, Yeboah E, Bingham WT, Ninan A 1982 Use of metoclopramide in preterm infants. Dev Pharmacol Ther 5:114-119

8. Hamill PVV, Drizd TA, Johnson CL, Reed RB, Roche AF, Moore WM 1979 Physical growth: National Center for Health Statistics Percentiles. Am J Clin Nutr 32:607-629

9. Dubois A, VanErdewegh P, Gardner JD 1977 Gastric emptying and secretion in Zollinger-Ellison syndrome. J Clin Invest 59:1255-263

10. Dubois A, Natelson B, VanErdewegh P, Gardner JD 1977 Gastric emptying and secretion in the rhesus monkey. Am J Physiol 232:E186-E192

11. Hildes JA, Dunlop DL 1951 Method for estimating the rates of gastric secretion and emptying. Can J Med Sci 29:82-89

12. George JD 1968 New clinical method for measuring the rate of gastric emptying: the double sampling test meal. Gut 9:237-242

13. Christie DL, Ament ME 1976 A double blind crossover study of metoclopramide versus placebo for facilitating passage of multipurpose biopsy tube. Gastroenterology 71:726-728

14. Cohen S, Morris DW, Schoen HJ, DiMarino AJ 1976 The effect of oral and intravenous metoclopramide on human lower esophageal sphincter pressure. Gastroenterology 70:484-487

15. McCallum RW, Fink SM, Lerner E, Berkowitz DM 1983 Effects of metoclopramide and bethanechol on delayed gastric emptying present in gastroesophageal reflux patients. Gastroenterology 84:1573-1577

16. Dubois A, Gross HA, Ebert MH, Castell DO 1979 Altered gastric emptying and secretion in primary anorexia nervosa. Gastroenterology 77:319-323

17. Dubois A, Castell DO 1981 Abnormal gastric emptying response to pentagastrin in duodenal ulcer disease. Dig Dis Sci 26:292-296

18. Sasaki H, Nagulesparan M, Dubois A, Vasquez B, Straus E, Sievers ML, Unger RH 1983 Inhibitory effect of intragastric glucose on gastric acid secretion and gastric emptying of liquids in man. Dig Dis Sci 28:502-506

19. Cooke AR, Clark ED 1976 Effect of first part of duodenum on gastric emptying in dogs: response to acid, fat, glucose, and neural blockade. Gastroenterology 70:550-555

20. Kelly KA Motility of the stomach and gastroduodenal function. In Johnson LR (ed) Physiology of the Gastrointestinal Tract. Raven Press, New York, 1981, p 396

21. Valenzuela JE 1976 Dopamine as a possible neurotransmitter in gastric relaxation. Gastroenterology 71:1019-1022

22. Hyman PE, Feldman EJ, Ament ME, Byrne WJ, Euler AR 1983 Effect of enteral feeding on the maintenance of gastric acid secretory function. Gastroenterology 84:341-345

23. Harada T, Hyman PE, Everett S, Ament ME 1984 Meal-stimulated gastric acid secretion in infants. J Pediatr 104:534-538

24. Cavell B 1983 Post-prandial gastric acid secretion in infants. Acta Paediatr Scand 72:857-860

25. Terrin BN, McWiliams NB, Maurer HM 1984 Side effects of metoclopramide as an antiemetic in childhood cancer chemotherapy. J Pediatr 104:138-140

26. Fournier A, Pauli A, Ducoulombier H, Cousin J 1969 Effects of overdose of metoclopramide in children: report of nine clinical cases. Pediatrie 24:779805

27. Witzel K 1972 Hyperkinetic dystonia in children due to metoclopramide. Mschr Kinderheilk 102:61-64

28. Casteels-Van Daele M, Jaeken J, Van der Schueren P, Zimmerman A, Van den Bon P 1970 Dystonic reactions in children caused by metoclopramide. Arch Dis Child 45:130-133

29. Schvartsman S, Costa Vaz TA, Sipel S, Sobrinho Netto AH 1972 Acute metoclopramide intoxication in children. Pediatr Prac 43:29-32

30. Low LCK, Goel KM 1980 Metoclopramide poisoning in children. Arch Dis Child 55:310-313 